\title{
COMPETÊNCIAS GERENCIAIS DE ENFERMEIRAS: UM NOVO VELHO DESAFIO?
} MANAGEMENTAL ABILITIES OF THE NURSE: THE NEW AND OLD CHALLENGE?
COMPETENCIA EN LA GERENCIA DE ENFERMERÍA: UN NUEVO ANTIGUO DESAFIO?

\author{
Isabel Cristina Koweal Olm Cunha ${ }^{1}$,Francisco Rosemiro Guimarães Ximenes Neto
}

\begin{abstract}
${ }^{1}$ Enfermeira. Doutora em Saúde Pública. Professora Adjunta do Departamento de Enfermagem. Coordenadora do Curso de Especialização em Gerenciamento de Serviços de Enfermagem da Universidade Federal de São Paulo (UNIFESP). Diretora da Faculdade de Enfermagem da Universidade Santo Amaro (UNISA).

${ }^{2}$ Enfermeiro. Sanitarista. Docente do Curso de Enfermagem da Universidade Estadual do Vale do Acaraú (UVA). Preceptor de Enfermagem da Residência em Saúde da Família da Escola de Formação em Saúde da Família, Sobral - CE.
\end{abstract}

PALAVRAS-CHAVE: Enfermagem. Competência profissional. Administração de pessoal. Gerenciamento de prática profissional.
RESUMO: Artigo de reflexão sobre a atuação do enfermeiro como gerente da assistência de enfermagem no atual mundo globalizado e com enormes demandas. Discute a relevância do preparo deste profissional para exercer seu papel no contexto de competências gerenciais, hoje amplamente difundidas como modelo de gestão. Destaca a importância do desenvolvimento de competências gerenciais nos enfermeiros desde a formação na graduação e de forma contínua nos serviços.
KEYWORDS: Nursing. Professional competence. Personnel management. Practice management.
ABSTRACT: This article is a reflection about the nurse's role as a manager of care in the current globalized world with its subsequent demands. It discusses the relevance of the professional education process in order for the nurse to play his/her role in the context of managerial competences, which are currently widely diffused as a management model. It also highlights the relevance of developing management competencies for nurses after the baccalaureate and in the permanent on the job educational processes.

PALABRAS CLAVE: RESUMEN: Este es un artículo de reflexión sobre el rol de la enfermera en la administración de la Enfermería. Competencia atención de enfermería en un actual mundo globalizado con grandes demandas. Discute la relevancia de profesional. Administración del la preparación de este profesional para ejercer su rol en el contexto de las competencias del gerenciamiento, personal. Manejo práctico. hoy ampliamente difundida como un modelo gerencial. Destaca la relevancia del desarrollo de las competencias en la gerencia para las enfermeras desde su formación a partir de la graduación y de una forma continua en los servicios de la institución.

Endereço: Isabel Cristina Kowal Olm Cunha Av. Vereador José Diniz, 1312

04604-001 - Alto da Boa Vista, São Paulo, SP.

E-mail: icris@denf.epm.br
Artigo original: Reflexão teórica

Recebido em: 13 de março de 2005.

Aprovação final: 12 de Julho de 2006.

Texto Contexto Enferm, Florianópolis, 2006 Jul-Set; 15(3): 479-82. 


\section{INTRODUÇÃO}

O mundo, neste novo milênio, passa por inúmeras transformações, mudando paradigmas e exigindo das pessoas e, sobretudo, das organizações, novas posturas. Hoje, o significado de palavras como globalização, conhecimento, competências, liderança, competitividade, tem permeado a agenda dos gestores nas empresas. Neste contexto, novas tendências para a gestão tomam conta do mercado, livros de auto-aju$\mathrm{da}$ ensinam o auto-desenvolvimento e os profissionais se vêem às voltas com aprender mais e mais para responder a essas demandas.

Os serviços de saúde, em especial os hospitais, que tradicionalmente procuram adequar-se aos novos modelos advindos da indústria, têm procurado incorporar essas novas tendências. Assim, novas ferramentas gerenciais como o balanced score-card, a gestão do conhecimento, da informação e das competências, a liderança coach, as unidades de negócios, vem sendo rapidamente introduzidos nos hospitais, modificando o panorama desta administração antes relegada a modelos muitas vezes empíricos e pouco profissionalizados.

Neste contexto de mudanças constantes, o perfil exigido das pessoas sofreu alterações, uma vez que as empresas necessitam de trabalhadores que possam responder com rapidez à elas. Assim, adaptar-se a novas situações, ser flexível e ter capacidade de relacionamentos, assumir desafios, entre outras, parecem ser requisitos imprescindíveis ao gestor neste novo milênio.

O enfermeiro como gestor da assistência de enfermagem em sua prática diária, requer este preparo adequado ao momento atual. Assim, contribuir para o debate das competências gerenciais dos enfermeiros, através da análise de alguns desses aspectos é o objetivo deste trabalho.

\section{A QUESTÃO DAS COMPETÊNCIAS}

A busca constante pela qualidade e excelência dos serviços trouxe mudanças nos modelos de gestão e, conseqüentemente, a forma de gerir as pessoas também mudou. $\mathrm{O}$ investimento nas pessoas é hoje valorizado, uma vez que tem ocorrido forte tendência de abandonar o enfoque científico da administração, por um enfoque mais sofisticado das relações humanas. ${ }^{1}$

As três principais mudanças pelas quais passa a área de gestão de pessoas são "a alteração no perfil das pessoas exigido pelas empresas, o deslocamento do foco da gestão de pessoas por meio do controle para o foco por meio do desenvolvimento e a maior participação das pessoas no sucesso do negócio ou da empresa". 2:35 Passam a ter valor então as competências que o indivíduo possui, e que o qualificam a realizar algo.

Competência tem significados distintos, tanto ligados às tarefas e aos seus resultados, como às características das pessoas. Desta forma, a troca de competências ocorre quando existe uma interação das pessoas com o ambiente organizacional..$^{2-3}$ Competência tem sido definida como um "saber agir responsável e reconhecido que implica mobilizar, integrar, transferir conhecimentos, recursos, habilidades, que agreguem valor econômico à organização e valor social ao indivíduo". 3:21

A literatura tem alinhado a competência gerencial à empresarial, ao definir que competência gerencial é um "conjunto de conhecimentos, habilidades e atitudes que os gerentes desenvolvem para assegurar a competência empresarial" "4:13 Assim, a competência pode ser classificada portanto sob o ponto de vista pessoal - competências essenciais - relacionadas ao indivíduo, à equipe e seu desenvolvimento, e do ponto de vista empresarial - competências organizacionais - essas relacionadas às estratégias corporativas. ${ }^{5}$

Ainda no final da década passada, sobre a questão das competências na área da saúde destaca-se a importância das universidades, principal recurso para a formação de profissionais qualificados, para criar ambientes onde fosse possível desenvolver competências. ${ }^{6}$ Neste aspecto, enfatizou a necessidade de parcerias com os serviços no sentido de se focar a aplicação do conhecimento ou pesquisa aplicada, que abriria espaço para o desenvolvimento de competências. Nesse aspecto, autores também dão ênfase à necessidade de se ter situações profissionais para este desenvolvimento. ${ }^{3-4,7}$

A gestão de competências gerenciais, ao abordar as correntes de estudos americana, latino-americana, francesa e australiana destaca as contribuições de alguns autores que buscam abordar as competências numa visão compartilhada.7 "Nesse contexto, as competências se desenvolvem por meio da interação entre as pessoas no ambiente de trabalho, privilegiando a questão da complementaridade; ou seja, não se limitam ao desenvolvimento de um perfil idealizado de gestor (super-homem) nem a listas infindáveis de atributos, mas se traduzem em práticas gerenciais complementares ou em ações gerenciais articuladas (consolidação de competências coletivas)" 7:60

Por outro lado, muitos autorestêm enfatizado a necessidade do desenvolvimento de competências es- 
pecíficas individuais, relacionadas à pessoa e à empresa, com os quais concordamos, por acreditar que no contexto da gestão é necessário que o gestor procure o seu auto-desenvolvimento bem como o do seu grupo. ${ }^{3,4,8}$ Estes ainda tem destacado competências individuais necessárias ao gestor como liderança, persuasão, trabalho em equipe, criatividade, tomada de decisão, planejamento e organização e determinação. $3,4,8$ As competências profissionais também são assim elencadas: "saber agir, mobilizar, comunicar, aprender, comprometer-se, assumir responsabilidades e ter visão estratégica". $3: 22$

O desenvolvimento das pessoas no contexto das organizações, neste milênio competitivo e em ambientes de constante mudança, está intimamente ligado ao desenvolvimento de competências. ${ }^{8}$ As empresas que mais rapidamente se adequarem à esta nova necessidade, com certeza, sentirão a diferença.

\section{As competências na enfermagem}

Dentro da equipe multiprofissional que se constitui na força de trabalho hospitalar, a equipe de enfermagem assume papel de destaque uma vez que se constitui no maior percentual do quadro de pessoal destas instituições através dos enfermeiros, técnicos e auxiliares de enfermagem.

Aos enfermeiros cabem entre outras, tarefas diretamente relacionadas com sua atuação junto ao cliente, bem como a liderança da equipe de Enfermagem e o gerenciamento dos recursos - físicos, materiais, humanos, financeiros, políticos e de informação - para a prestação da assistência de enfermagem." Do enfermeiro é exigido conhecimento (que conheça o que faz), habilidades (que faça corretamente) e tenha atitudes adequadas para desempenhar seu papel objetivando resultados positivos. É, portanto, exigido que ele seja competente naquilo que faz, bem como garanta que os membros da sua equipe tenham competência para executarem as tarefas que lhes são destinadas. ${ }^{9}$ Constitui-se portanto, um desafio definir as competências necessárias aos enfermeiros, bem como de estabelecer-se mecanismos para seu desenvolvimento dentro e fora das instituições. Destaca-se ainda que entre as funções de administração do enfermeiro está a de garantir que os membros de sua equipe tenham competência para executarem as tarefas que lhes são destinadas. ${ }^{9}$

A formação de enfermeiros, neste contexto de transformações por que passa o mundo e, especificamente, os serviços de saúde, vem sendo constantemente discutida, e tem apontado para a necessidade de mudanças. ${ }^{10-11}$ Nessa perspectiva, o ensino baseado em competências vem sendo apontado como uma das estratégias para estas mudanças, tendo sido indicado nas Diretrizes Curriculares para os Cursos de Graduação em Enfermagem, atualmente em vigor. ${ }^{12}$

Nelas, as habilidades e competências gerais propostas são: a atenção à saúde, a tomada de decisões, a comunicação, a liderança, a administração e gerenciamento e a educação permanente. Há ainda um elenco de mais trinta e três outras denominadas de específicas.

\section{Competências gerenciais dos enfermeiros}

O enfermeiro, como o gerente da assistência de enfermagem prestada ao paciente, requer o conhecimento, as habilidades e as atitudes que possibilitarão com que exerça seu trabalho objetivando resultados com eficiência. Este papel gerencial, amplamente discutido desde anos passados, passa pelo próprio desenvolvimento da enfermagem como ciência, que de uma prática "antes independente, torna-se subordinada à prática médica” ${ }^{13: 223}$ Estudos sobre a prática gerencial e o mundo do trabalho na Enfermagem, tem mostrado que as competências constituem um tema de discussão imediata a fim de se dar respostas às necessidades desta prática. ${ }^{1415}$ Autores têm abordado individualmente competências como a interpessoal, a liderança, a motivação da equipe, a comunicação, entre outras, também importantes, num claro sinal que discuti-las tem sido uma necessidade percebida e manifestada. ${ }^{16-17}$

O Nursing Leadership Institute, nos Estados Unidos da América, criou um modelo de competências para o enfermeiro gestor, após pesquisas com enfermeiras gerentes naquele país. Nele, foram identificadas seis competências que desdobram-se em vários itens, e que podem ser assim traduzidas: poder pessoal, efetividade interpessoal, gestão financeira, gestão de recursos humanos, cuidados com o staff, com os pacientes e consigo mesmo, pensamento sistematizado e como atributos adicionais destaca o otimismo e a resiliência. ${ }^{18}$ Este modelo dá conta de competências que envolvem aspectos da pessoa individualmente, dela com o grupo e dela na sua atuação na empresa, e parece responder a alguns questionamentos que este pal-

\footnotetext{
*Sanna MC. Oprocesso de trabalho gerenciar do enfermeiro. Aula ministrada no Curso de Especialização em Gerenciamento de Serviços de Enfermagem da UNIFESP em 2004. Disponível em powerpoint [material não publicado].
}

Texto Contexto Enferm, Florianópolis, 2006 Jul-Set; 15(3): 479-82. 
pitante tema nos remete.

Muitas são as competências que parecem ser necessárias ao enfermeiro na sua prática profissional e desenvolvê-las é, pois um grande desafio tanto dos órgãos formadores, como dos serviços na perspectiva da educação permanente e torna-se responsabilidade de todos estes atores: docentes, enfermeiros dos serviços e do próprio aprendiz.

\section{CONSIDERAÇÕES FINAIS}

Assim, podemos inferir que apesar de existirem algumas certezas, ainda não há consenso sobre todas as competências gerenciais que sejam indispensáveis ao enfermeiro gestor no contexto atual dos serviços de saúde em nosso país. Todavia há que se estimular esta discussão a fim de que o debate possa despertar-nos a todos, para não só no âmbito gerencial defini-las, mas principalmente como desenvolvê-las nos enfermeiros.

\section{REFERÊNCIAS}

1 Lewis G, Crozier G. Teste suas competências pessoais. São Paulo (SP): Publifolha; 2002.

2 Dutra JS. Gestão por competências: um modelo avançado para o gerenciamento de pessoas. São Paulo: Editora Gente; 2001.

3 Fleury A, Fleury MTL. Estratégias empresariais e formação de competências: um quebra cabeça caleidoscópico da indústria brasileira. São Paulo (SP): Atlas; 2004.

4 Boog GG. O desafio da competência: como enfrentar as dificuldades do presente e preparar-se para o futuro. São Paulo (SP): Ed. Nova Cultural; 2004.

5 Brandão HP, Guimarães TA. Gestão de competências e gestão de desempenho: tecnologias distintas ou instrumentos de um mesmo constructo? RAE. 2001 JanMar; 41 (1): 8-15.

6 Alperstedt C. A questão das competências na área da Saúde: um convite à reflexão. Mundo da Saúde. 1999 Maio-Jun; 23 (3): 185-6.
7 Bitencourt CC. A gestão de competências gerenciais e a contribuição da aprendizagem organizacional. RAE. 2004 Jan-Mar; 44 (1): 58-69.

8 Dutra JS. Competências: conceitos e instrumentos para a gestão de pessoas na empresa moderna. São Paulo (SP): Atlas; 2004.

9 Marquis BL, Huston CJ. Administração e liderança em enfermagem: teoria e aplicação. Porto Alegre (RS): Artes Médicas; 1999.

10 Domenico EDL, Ide CAC. Referências para o ensino das competências na enfermagem. Rev. Bras. Enferm. 2005 Jul-Ago; 58 (4): 453-7.

11 Nascimento ES, Santos GF, Caldeira VP, Teixeira VMN. Formação por competência do enfermeiro: alternância teoria-prática, profissionalização e pensamento complexo. Rev. Bras Enferm. 2003 Jul-Ago; 56 (4): 447-52.

12 Ministério da Educação (BR), Conselho Nacional de Educação, Câmara deEducação Superior. Resolução CNE/CES $\mathrm{n}^{\circ} 3$ de 9 de novembro de 2001. Dispõe sobre as Diretrizes Curriculares para os Cursos de Graduação em Enfermagem. Diário Oficial da União, 9 Nov 2001. Seção 1.p.37.

13 Formiga JMM, Germano RM. Por dentro da história: o ensino de Administração em Enfermagem. Rev. Bras. Enferm. 2005 Mar-Abr; 58 (2): 222-6.

14 Witt RR, Almeida MCP. O modelo de competências e as mudanças no mundo do trabalho: implicações para a enfermagem na atenção básica no referencial das funções essenciais de saúde pública. Texto Contexto Enferm. 2003 Out-Dez; 12 (4): 559-68.

15 Kurcgant P, Ciampone MHT. A pesquisa na área de gerenciamento em enfermagem no Brasil. Rev. Bras. Enferm. $2005 \mathrm{Mar} / \mathrm{Abr} ; 58$ (2): 161-4.

16 Fernandes JD, Araújo FA, Fernandes J, Reis LS, Gusmão MCCM, Santana N. Competência interpessoal nas práticas em saúde: o individual e o coletivo organizacional. Texto Contexto Enferm. 2003 Abr-Jun; 12 (2): 210-5.

17 Cunha KC, organizador. Gerenciamento na Enfermagem: novas práticas e competências. São Paulo (SP): Martinari; 2005.

18 Nursing Leadership Institute. The nursing leadership institute competency model [acesso em 2006 Fev 28]. Disponível em: http://www.fau.edu/nli/model.html 